\title{
A PECADORA QUEIMADA E OS ANJOS HARMONIOSOS: UMA ANÁLISE DO SORRISO DA PECADORA COMO MÁQUINA DE GUERRA
}

\section{THE BURNED SINNER AND THE HARMONIOUS ANGELS: AN ANALYSIS OF THE SINNER'S SMILE AS A WAR MACHINE}

\author{
Ana Cláudia Andruchiw* \\ $U E P G$
}

\author{
Johny Adelio Skeika** \\ UEPG
}

\section{Silvana Oliveira*** \\ UEPG}

\begin{abstract}
Resumo: Este artigo teve como objeto de estudo a única produção teatral de Clarice Lispector, a peça $A$ Pecadora queimada e os Anjos harmoniosos (1964). O objetivo principal consistiu em analisar o sorriso da protagonista como única via de expressão em todo o ato, como uma manifestação de resistência contra o sistema social que organiza sua morte. A conclusão a que se chegou na análise do sorriso da pecadora é de que ele se manifesta como a pequena máquina de guerra clariceana, subvertendo e alterando a expectativa de punição e restauração da ordem previstas pelo ato condenatório. Considerou-se essa manifestação como uma guerrilha, silenciosa e criativa, que se mobiliza contra o sistema estatal. Nesta análise, valeu-se do pensamento de Gilles Deleuze e Felix Guattari em Mil Platôs, sobretudo no platô 12, 1227 - Tratado de Nomadologia: a máquina de guerra, assim como algumas noções conceituais do Teatro de Crueldade, de Antonin Artaud.
\end{abstract}

Palavras-chave: Clarice Lispector. A Pecadora queimada e os Anjos harmoniosos. Máquina de Guerra.

\begin{abstract}
This article aimed to analyze Clarice Lispector's single theatrical work, the play "The burnt sinner and the harmonious angels". The main focus lied on the analysis of the main character's smile as the sole mean of expression in the whole act, as a manifestation of resistance against the establishment that organizes her death. The conclusion reached in the analysis of the sinner's smile reveals itself to be Clarice's small war machine which subverts and changes the expectation not only for punishment but also for the restoration of the social order expected by the condemnatory act. This manifestation
\end{abstract}

\footnotetext{
* Mestre em Estudos da Linguagem pela Universidade Estadual de Ponta Grossa (UEPG). E-mail: <anac.andruchiw@hotmail.com>.

** Doutor em Estudos Literários pela Universidade Estadual de Londrina (UEL). Bolsista PNPD do Programa de Pós-Graduação em Estudos da Linguagem (UEPG). ORCID: https://orcid.org/0000-0001-8632-0264. E-mail: <jhonyskeika@gmail.com>.

${ }^{* * *}$ Doutora em Teoria e História Literária pela Universidade Estadual de Campinas (UNICAMP). Professora Associada da Universidade Estadual de Ponta Grossa (UEPG). ORCID: https://orcid.org/0000-0002-3429-8541. E-mail: <oliveira_silvana@hotmail.com>.
} 
was considered a guerilla act, silent and inventive, which mobilizes against the state establishment. For such analysis, Deleuze and Guattari's thinking in A Thousand Plateaus, especially in plateau 12,227 Nomadology: The War Machine, was employed, as well as some concepts from the Theatre of Cruelty of Antonin Artaud.

Keywords: Clarice Lispector. The burnt sinner and the harmonious angels. War Machine.

\section{INTRODUÇÃO}

O único trabalho do gênero dramático de Clarice Lispector foi produzido durante o período de exílio da escritora, entre os anos de 1946 a 1949, na cidade de Berna na Suíça. Dizemos exílio para destacar seu afastamento das irmãs e do contexto cultural a que estava apegada no Brasil, mas é importante destacarmos que Clarice viajava com seu marido, o diplomata Maury Gurgel Valente. Seu estado de espírito, no entanto, é de estranhamento em relação ao ambiente diplomático, daí uma certa associação direta da solidão e da introspecção ao projeto de escrita da peça teatral A Pecadora queimada e os anjos harmoniosos.

Em um primeiro momento, a publicação da peça só ocorreu na primeira edição da coletânea de contos A legião estrangeira, em 1964, em uma seção intitulada "Fundo de Gaveta". Nas edições seguintes, a peça foi retirada e só obteve maior divulgação após a morte da escritora, especificamente na publicação de Outros escritos, organizado por Tereza Montero e Lícia Manzo, em 2005, e anos mais tarde a peça reaparece na coletânea organizada por Benjamin Moser, Clarice Lispector - Todos os Contos, em 2016.

No prefácio da seção "Fundo de Gaveta”, a escritora justificou a inclusão da peça na publicação como um material escrito como distração, feito de modo despretensioso: "Por que publicar o que não presta? [...]. Gosto de um modo carinhoso do inacabado, do malfeito" (LISPECTOR, 1964, p. 127). Clarice classificou o trabalho como ruim e inacabado e resistiu em publicá-lo, o que talvez justifique o fato de o texto ser pouco conhecido pelo público leitor e ter pouca expressividade nos estudos e atenção crítica. O professor Earl E. Fitz¹, precursor nos estudos sobre a peça, e sua tradutora Eneida Nalini ressaltam a negligência de análises críticas envolvendo o texto:

Quase totalmente desprezado no crescente corpus de estudos críticos devotados aos seus trabalhos, A pecadora queimada e os anjos harmoniosos - o esforço mais prematuro conhecido de Clarice Lispector na literatura dramática - merece a atenção do leitor [...]; esse complexo, enigmático drama, com somente quatorze páginas, mas engajando não menos que treze personagens ou vozes, constitui um experimento clariceano com um modo diferente de expressão. Essa tentativa a permitiria se dirigir de uma maneira das mais explícitas politicamente (gênero, sexualidade e poder) que deu forma ao seu trabalho, embora indiretamente, até esse ponto; [...] esse texto lamentavelmente negligenciado, que surpreendentemente não produziu nenhum estudo crítico conhecido, revela uma Clarice Lispector mais diretamente preocupada com os assuntos urgentes relacionados a questões

${ }^{1}$ Dr. Earl E. Fitz é professor de Português, Espanhol e Literatura Comparada na Universidade de Vanderbilt, Estados Unidos da América. 
sociopolíticas de gênero e poder do que já vistos anteriormente. (FITZ; NALINI, 2011, p. 131-133).

Importante destacarmos que essa peça de Clarice, embora não goze da mesma popularidade de outros textos da autora, ainda assim tem recebido atenção crítica considerável nos últimos anos. A encenação da vida por meio da tragédia clariceana, mesmo que marcada de grande silêncio, muito fala sobre a tensão das relações de poder que permeiam os discursos da sociedade. Ainda que a autora, de modo geral, tratasse com sutileza as questões de gênero, poder e sexualidade, a peça soa como uma ácida crítica para a sociedade.

A Pecadora Queimada e os Anjos Harmoniosos pode ser lida como uma peça de transição, uma chave que revela o crescimento de Clarice Lispector como uma escritora criativa, e uma comentarista sociopolítica, especificamente no que diz respeito ao papel das mulheres na sociedade. (FITZ; NALINI, 2011, p. 132).

A tragédia de Clarice arquiteta-se como um sutil escândalo na medida em que se apresenta como uma forma de denúncia social e efetiva-se como modo de resistência. Nessa perspectiva, esse texto de Clarice alinha-se ao recorrente tratamento da condição feminina no contexto da vida brasileira; as mulheres são figuras recorrentes na produção clariceana e a "pecadora queimada” evoca uma linhagem de personagens mulheres fora do papel que se espera delas. Desde Joana, de Perto do Coração Selvagem, de 1947, até Macabéa, de A hora da estrela, de 1977, o leitor é colocado diante de identidades femininas capazes de problematizar a expectativa de papéis no contexto social de uma sociedade patriarcal e calcada na limitação de ação e espaço às mulheres.

Ambientada em contexto de Idade Média, a peça A Pecadora queimada e os anjos harmoniosos é constituída de apenas um único ato e contém 13 personagens: A Pecadora, o Esposo, o Amante, o Sacerdote, o Primeiro e o Segundo Guarda, Anjos invisíveis, os Anjos nascendo e Anjos nascidos; os personagens o Povo, a Mulher do povo, Mulheres do povo, a Criança com sono representam o coro, portanto a unicidade de suas vozes expressa o desejo coletivo pela ordem. O conflito desenvolve-se, também, em um único cenário, em um pátio, onde se alocam todas as personagens.

O enredo da peça gira em torno do julgamento e da condenação de uma mulher à fogueira - a sentenciada é acusada de adultério - no caso, devido a uma dupla traição, pois o amante ignorava o fato de a mulher ser casada e alega também ter sido enganado. O julgamento é convocado pelo Esposo que, de forma pública, expõe a conduta da mulher e clama por justiça; como num ritual religioso, presidido por um sacerdote, a Pecadora é imolada como forma de purificação do pecado. A condenação e a execução da mulher são visualizadas e acompanhadas pelos bramidos do povo que também anseia pela punição; os anjos, de alguma forma, dependem também dessa morte para que possam nascer e restabelecer a harmonia na sociedade.

As ações do drama são delimitadas dentro do espaço de um palco e, de acordo com Aristóteles (2015, p. 213), são efetivadas “não por narrativa, mas mediante atores”. Dessa forma, como não há especificamente um narrador, os diálogos, os gestos e as ações das personagens são o sustentáculo da peça; desse modo, a expressividade das personagens compõe o centro da linguagem teatral. 
Entretanto, na tragédia de Clarice, todos os personagens, inclusive uma criança com sono, possuem a fala, apenas a personagem principal se mantém em silêncio durante todo o ato - o que se sabe dela é por meio da repercussão da fala dos outros personagens. Os traços de identificação da protagonista nos são apresentados a partir das representações de poder internalizadas por esses personagens; por eles sua intimidade é exposta, julgada e condenada. Fora o absoluto silêncio, a única outra expressão da protagonista é um sorriso que esboça ante as chamas.

\section{O SORRISO COMO ÚLTIMO DISCURSO}

O último discurso da supliciada seria dado no intuito de legitimar a justiça da sentença sobre sua morte, um reconhecimento verbal como uma confissão de que o crime não compensa; esse discurso final, o "arrependimento santo", seria como um efeito moral e educativo para o povo que visualiza o suplício. Nesse ponto, percebemos o ato clariceano subvertendo a tragédia, como gênero dramático, o qual traz a manifestação do sorriso em vez do "discurso do cadafalso", perturba a ação do exemplo a ser deixado, anula a cumplicidade da heroína com a fábula e a consequente evocação da moral da história. De todo modo, os espectadores da morte ansiavam pelas manifestações orais de dor, pois os murmúrios, penitências ou blasfêmias indicariam o destino perpétuo do agonizante: salvação ou danação eterna.

No entanto, o sorriso é a única frustrante expressão da condenada durante todo o ato; em meio ao discurso dos outros personagens, essa é a linguagem não verbal utilizada pela Pecadora momentos antes de sua morte: "mulher que sorri cheia de silêncio" (LISPECTOR, 2005, p. 52). Repleta de silêncio, a comunicação não verbal da protagonista se efetiva na peça como um mecanismo de linguagem corporal, escolha utilizada pela Pecadora como única via para um possível intercâmbio que se aproxime de algum entendimento do seu interior. O último discurso da supliciada, não codificável, torna seu destino eterno misterioso: "Sorris inacessível" (LISPECTOR, 2005, p. 52). Contudo, mesmo impenetrável, o sorriso é a voz da "estrangeira solitária” que, de alguma forma, se comunica, porém não é compreendido naquele sistema social: “Quem é essa estrangeira?” (LISPECTOR, 2005, p. 50). Desse modo, mesmo intraduzível, o sorriso responde à expectativa do olho coletivo, mas encontra na comunicação uma resistência que parte da linguagem pasteurizada pelo processo civilizatório.

A atitude da supliciada, de alguma maneira, ao furtar-se à manifestação verbal, mesmo que soe como uma perda de senso em articular as palavras, configura-se como uma espécie de desistência e/ou renúncia ao mecanismo de linguagem formal e, por isso, quase irracional, aproxima-se do primitivo, do lado animal do ser humano. Por esse prisma, a não linguagem da Pecadora ao sorrir diante da morte teria a potência de um devir animal, como uma recusa à fala da gente civilizada que executa sua vida em chamas. Assim, a revolta com a linguagem tange uma denúncia ao discurso dessa sociedade que, embora represente a harmonia no processo civilizatório, ao mesmo tempo se desdobra na "terrível harmonia” de uma sociedade que compactua com o discurso assassino.

Por essa concepção, a resposta primitiva de sorrir carregaria um sentido de ironia, na medida em que exporia a "humanização" dos donos do discurso em toda sua bestialidade e crueldade revestidas de decoro e decência. Com base nisso, o sorriso caracterizado como um 
devir animal se estabelece como máquina de guerra a minar o discurso do agenciamento de poder daquele sistema social.

O sorriso em seu aspecto ininteligível não se afeiçoa apenas como vingança ao discurso da máquina estatal. Por ser uma linguagem inacessível àquela comunidade medieval, o mecanismo de comunicação da personagem, ao impedir o entendimento, se realiza nisso mesmo, na desordem e na confusão das ideias:

Criança com sono: Ela está sorrindo.

Povo: Está sorrindo, está sorrindo, está sorrindo.

Povo: A que sorri esta mulher?

Primeiro e segundo guardas: Ao pecado.

Povo: A que sorri esta mulher?

Amante: Sorris porque me usaste para ainda viva seres pelo fogo ardida [...]. (LISPECTOR, 2005, p. 52-53).

Como vemos, por duas vezes, o Povo indaga sobre o motivo do sorriso da condenada, e o choque pela atitude da Pecadora é demonstrado por todos, que levantam conjecturas. Assim, o sorriso parece perturbar a lógica dos sentidos e pulveriza o sentimento da certeza nas coisas: “[...] encontra-se exatamente no ponto em que o espírito precisa de uma linguagem para produzir suas manifestações” (ARTAUD, 2006, p. 5). Enigmático, o sorriso como única linguagem corporal efetivada pela Pecadora ante sua violenta execução parece completamente incoerente com o contexto de morte e nos conduz, portanto, para uma zona indiscernível, proliferadora de múltiplos sentidos indizíveis.

A tragédia de Clarice traz em cena as vozes das personagens que pronunciam a linguagem articulada com toda sua eficácia dentro dos discursos. Do início ao fim do ato, suas palavras ecoam em diálogos da verdade das personagens com qualidade e erudição, mas a protagonista da cena se expressa por meio do silêncio e do sorriso, elementos cênicos que provocam a ideia de vazio, mas que, por sua vez, forjam um espaço de criação de significados. Para o teórico e dramaturgo Antonin Artaud, fundador do Teatro da Crueldade, essa é a linguagem teatral pura.

Artaud critica a soberania da palavra no teatro. Para ele, a cena como na vida deve ser preenchida com outras linguagens concretas que independem da palavra; ele considera que as manifestações não verbais extrapolam o limite da linguagem e assumem uma conexão com o espírito. Por conta disso, resgatam o poder de inquietar e encantar: “[...] é voltar-se contra a linguagem e suas fontes rasteiramente utilitárias, poder-se-ia dizer alimentares, contra suas origens de animal acuado, é, enfim, considerar a linguagem sob a forma do Encantamento" (ARTAUD, 2006, p. 21).

Por esse prisma, o sorriso na peça, mesmo que gere significações, pelo magnetismo que ele provoca, para esta leitura, se manifesta como um gesto de encantamento com a possibilidade de atingir domínios inexplorados do pensamento. Ele se estabelece como uma linguagem diretamente direcionada ao espírito, ao arrebatamento, pois suscita indagação, inquietação e indignação dos espectadores, exigindo o exercício de criação de sentidos e significações "Rompe enfim a sujeição intelectual à linguagem, dando o sentido de uma intelectualidade nova e mais profunda” (ARTAUD, 2006, p. 44). Dito de outro modo, o discrepante riso da protagonista no contexto de sua execução expressa o que a palavra não consegue alcançar. $\mathrm{O}$ 
sorriso diante da morte provoca uma espécie de vácuo em que a linguagem se esvazia e atinge o mais profundo dos pensamentos: “[...] uma figura que mascare o que gostaria de revelar têm mais significação para o espírito do que as clarezas proporcionadas pelas análises da palavra” (ARTAUD, 2006, p. 35).

Na concepção de que o silêncio é o espaço que permite que a linguagem signifique, gerando assim múltiplos sentidos, na perspectiva de Artaud, o sorriso (como uma linguagem não verbal) também é a expressão que provoca a ideia lacunar que possibilita a reação de proliferação de pensamentos outros, pensamentos descolonizados. Para ele: "A expressão verdadeira esconde o que ela manifesta. Opõe o espírito ao vazio real da natureza, criando por reação uma espécie de cheia no pensamento" (ARTAUD, 2006, p. 35). Esse outro recurso no teatro, que não o da linguagem falada, é uma das preocupações do dramaturgo, que considera que os gestos, sem significações associadas, e outras expressões como mímicas, sonoridades, gritos e onomatopeias, manifestam a poesia cênica, a linguagem como encantamento.

O sorriso como única expressão cênica da protagonista parece superar os limites da linguagem, como uma linguagem até então inoperante, infundada; conduz para que se pense em uma forma de expressão que existe aquém ou além da linguagem, o que ainda não possui um formato verbal: "É aí que a linguagem se torna intensiva, puro contínuo de valores e de intensidades. É aí que toda língua se torna secreta, entretanto, não tem nada a esconder, ao invés de talhar um subsistema secreto na língua” (DELEUZE; GUATTARI, 1995, p. 35).

Ao fugir do compreensível como algo superior à linguagem inteligível, o sorriso da Pecadora, como a linguagem que nos escapa, estabelece-se ao nível da experimentação. Assim, localizado no ponto da abstração das ideias, não interpretável, o sorriso da adúltera se expande livre para um novo tipo de realidade, para um grau de experimentação e potencialidades em devir. De acordo com Artaud (2006),

[...] a linguagem clara que impede esse vazio impede também que a poesia apareça no pensamento. É por isso que uma imagem, uma alegoria, uma figura que mascare o que gostaria.789 de revelar têm mais significação para o espírito do que as clarezas proporcionadas pelas análises da palavra. (ARTAUD, 2006, p. 35).

Mesmo que em nível de experimentação, ao sermos atraídos a vivenciar essa experiência - sem pretender interpretar ou decifrar o sorriso de morte da Pecadora - mas a partir da apropriação da experiência proporcionada pelos meandros do sorriso, somos impelidos a refletir e explorar a potência dessa não linguagem, a partir da fruição da leitura da cena, uma vez que “[...] a experimentação só existe, enquanto experiência que pode ser descrita, porque há uma apropriação. Uma vez concluída, ela apenas propõe e potencializa movimentos vindouros para novas experimentações” (SKEIKA; OLIVEIRA, 2014, p. 12). Partindo disso, buscamos refletir sobre a única manifestação cênica da protagonista que articula uma linguagem com o fora da ordenação da linguagem humana.

\section{O SORRISO COMO MÁQUINA DE GUERRA}

O sorriso da Pecadora, em desarmonia com a tragédia, soa como uma necessidade da natureza em expressar algo e, ao apresentar-se como única manifestação da personagem antes 
de ser executada, o sorriso é o discurso que responde à morte com uma linguagem secreta que se abre a inúmeras possibilidades significativas. Por essa óptica, como uma linguagem não clara e que exige o exercício de fazer pensar, aqui, ele se manifesta como uma linguagem que responde à morte de modo ativo e criador, configurando-se como uma potência de fuga: “Na palavra de ordem, a vida deve responder à resposta da morte, não fugindo, mas fazendo com que a fuga aja e crie” (DELEUZE; GUATARRI, 1995, p. 49). O sorriso, à vista disso, se constitui como uma linguagem desterritorializada com a potência de colocar em fuga o sistema de morte.

Mesmo que destoante do contexto de morte, o silencioso sorriso concerne à postura da Pecadora e, pela perspectiva artaudiana de "encantamento", dirige-se direto ao pensamento, desestabilizando o conforto da sua ordem intelectual. O sorriso conecta-se efetivamente ao pensamento colonizado e, por isso, assume-se como máquina de guerra dentro de um regime já sedentarizado. O riso de morte responde ao sinal de ameaça e se coloca em modo de fuga, mas não como covardia, pois não foge antes de sabotar o sistema déspota. Assim, como um devir minoritário, reage à morte reivindicando a vida e não se entrega sem antes minar a máquina do estado: "Fugir não é renunciar às ações, nada mais ativo que uma fuga. É o contrário do imaginário. É também fazer fugir, não necessariamente os outros, mas fazer alguma coisa fugir, fazer um sistema vazar como se fura um cano” (DELEUZE; PARNET, 1998, p. 49).

Aparentemente insano, o riso durante o suplício inutiliza o senhorio dos agentes de poder pela sua morte e nega a cumplicidade ao ritual de crueldade, o sorriso da morte funciona como uma manifestação de resistência. Para Orlandi (1995):

A censura é um sintoma de que ali pode haver um outro sentido. Na censura está a resistência. Na proibição está o “outro” sentido. E isso porque, como dissemos, a censura atinge a constituição da identidade do sujeito. A identidade, por seu lado, sempre em movimento, encontra suas formas de manifestação não importa em que situação particular de opressão. (ORLANDI, 1995, p. 118).

Ao silenciar e sorrir durante seu julgamento e morte, a Pecadora utiliza mecanismos da linguagem de resistência, deslocando os sentidos do interdito e reproduzindo o discurso reverso da censura. Desse modo, sua fala, seu corpo, sua morte e subjetividade, por mais que aparentem aprisionados, estão livres e sob seu domínio e controle: ela está inatingível, como bem percebeu o esposo traído.

A atitude da adúltera, ao sorrir enquanto morre, de algum modo, afirma sua impenitência; ao obedecer ao sacerdote em "tomar a morte como palavra”, a Pecadora recebe a sentença manifestando uma espécie de escárnio e/ou alegria, ao contrário do que se esperava.

Povo: A que sorri esta mulher?

Amante: Sorris inacessível, e a primeira cólera me possui. [...]. Por que estranha graça o pecado abjeto transfigurou-te nesta mulher que sorri cheia de silêncio?

Esposo: Ira impotente: ei-la sorrindo, de mim ainda mais ausente do que quando era de um outro. [...]. Ah, mecanismo cruel que desencadeei com meus lamentos de ferido. Pois eis que a tornei inatingível mesmo antes dela morrer. (LISPECTOR, 2005, p. 52). 
O questionamento das razões do sorriso sugere uma possível problematização, podendo desestabilizar o discernimento do senso comum e confundir a racionalidade do público; em certa medida, pode colocar em xeque a unicidade do processo de subjetivação do coletivo social. Por isso, o sorriso aqui considerado pela perspectiva de ciência nômade, ao confundir o olho coletivo, rebela-se numa conexão direta com o pensamento codificado, colonizado, daquele sistema social.

A possível ironia contida no riso que antecede a execução também não encerraria a silenciosa guerrilha. $\mathrm{O}$ sorriso antes da morte parece simbolizar um triunfo sobre a morte, mas não a morte da sentenciada, mas como uma libertação da mórbida existência daquela sociedade. A imagem do sorriso soa como uma graça: "Por que a estranha graça o pecado abjeto transfigurou-se nesta mulher que sorri cheia de silêncio?” (LISPECTOR, 2005, p. 52). Essa estranha transfiguração da Pecadora causa espanto, pois, ao receber a morte como pagamento pelo pecado, parece se expandir gloriosa, como a morrer em paz: "ESPOSO: E seus olhos brilham úmidos numa glória...” (LISPECTOR, 2005, p. 52).

O sorriso parece transcender a morte; dessa forma, converte a tragédia da supliciada a uma dádiva. Por essa óptica, o sorriso sugere que a Pecadora, pela via do pecado, consumida pelo fogo do desejo, viveu intensamente e agora morre gloriosa. Assim sendo, a desordem no pensamento dos corpos dóceis se efetiva na visualização da graça em morrer em pecado: "Como te reconhecer, se sorris toda santificada?” (LISPECTOR, 2005, p. 53). Com efeito, a partir do momento em que o olho coletivo tenta extrair o prazer na dor, ocorre uma falha no ritual de codificação, pois o olho apreciador percebe nessa espécie de "santificação" pelo sorriso a graça da vida na terra por seguir pela via dos "estranhos caminhos" do pecado (LISPECTOR, 2005, p. 47).

À vista disso, a máquina de guerra, conforme a propõe Deleuze e Guattari (1995), em Mil Platôs (Volume 5), principalmente no platô 12. 1227, "Tratado de Nomadodologia: A máquina de Guerra”, é acionada na medida em que possibilita uma conversão das ideias e o prazer do olho coletivo se transfigura como uma espécie de inveja de viver: "MULHER DO POVO: Todas essas palavras têm estranhos sentidos. Quem é essa que pecou e mais parece receber louvor do pecado?” (LISPECTOR, 2005, p. 122, grifo da autora). O sorriso da carne passiva enquanto morre, aparentemente, sujeita ao ritual de codificação, burla o código de filiação, desvenda, em certo sentido, um modo de existência livre do processo de recalcamento do desejo.

Esse paradoxo de sentimentos que podem se desencadear da visualização de uma cruel execução, que serviria para punir a impureza, o adultério e a desobediência às normas, em contraste com o sorriso da sentenciada antes da penalização, é, sobretudo, um dos principais elementos detonadores da máquina de guerra naquele sistema social. O sorriso da adúltera desautomatiza a memória coletiva do ritual de codificação. A lembrança da mulher que sorri antes de morrer queimada, pelo impacto da inversão da ordem das coisas, se fixa no imaginário social. A desestabilização da memória sobre o destino eterno dos pecadores poderia afrouxar o medo da repressão sobre a danação da alma e servir como um convite às desobediências. Essa quebra no processo de produção da memória coletiva poderia, gradativamente, arrastar a sociedade a uma contaminação coletiva de vivência em intensidade pela via do pecado. $\mathrm{O}$ sorriso, aqui visto como uma transgressão no ritual de crueldade, ao levantar o questionamento 
sobre os deslocamentos dos sentidos de arrependimento e prazer, pode facilitar a indisciplina ao processo de recalcamento dos desejos.

Assim, ao agir no imaginário popular, o sorriso cria uma falha na engrenagem, age como uma avaria diretamente nas principais peças de produção do agenciamento maquínico do poder, interferindo na perpetuação do processo de memória de codificação e domesticação dos corpos. O sorriso é a pequena máquina de guerra clariciana, operando por resistência ao corpo que queima e ao desejo de penitência que todos os olhares exigem da pecadora; seu sorriso não é indiferença ou alienação, é a sua linha de fuga, é o movimento que a faz com que toda a expectativa de punição exemplar e retomada da "ordem” desejada seja colocada em questão e, num certo sentido, subvertida. O sorriso da pecadora tira a razão dos demais e esvazia seus gestos. Os anjos que ainda não haviam nascido validam a ideia do homem na terra como "roda" na engrenagem da terrível harmonia: "Retira a mão do rosto, esposo [...] que és ínfima, ínfima, ínfima roda da terrível, terrível harmonia” (LISPECTOR, 2005, p. 53). Assim, ao atingir a "roda”, base essencial que carrega o mecanismo do aparelho estatal, a funcionalidade da linguagem silenciosa do sorriso, como ferramenta da máquina de guerra, de modo não violento, mas clandestino, ao confundir a certeza das coisas no pensamento olho coletivo, pode gerar naquela sociedade uma possível "pane” no sistema, uma anomalia no processo de recalcamento desejo.

Com o potencial de um devir minoritário, o sorriso também suscita que se descodifiquem as marcas do aniquilamento identitário que a Pecadora sofreria com sua morte, uma espécie de erradicação e/ou desonra histórica da adúltera naquela sociedade. Sua aparente passividade ao sorrir antes de morrer escapa ao domínio da ordem da sua sentença de morte. De algum modo, o sorriso desvincula a morte da pena e, ao desautorizar sua condenação, implica desobediência à sentença: "Pois a questão não era: como escapar à palavra de ordem? mas como escapar à sentença de morte que ela envolve, como desenvolver a potência de fuga?” (DELEUZE; GUATTARI, 1995, p. 49).

Ao perturbar os pensamentos dos espectadores de sua morte, provocando-lhes indagações sobre o futuro, a adúltera poderia suscitar reflexões históricas sobre aquela que viveu a partir da natureza das próprias leis, aquela que não foi pertença do desejo alheio: “[...] aquela que não foi de ninguém [...]”; “[... ] aquela que na verdade a ninguém deu” (LISPECTOR, 2005, p. 51; 55). A sentenciada, por essa perspectiva, cria com sua morte outra identidade histórica: “Afinal que sucede que esta mulher que ser queimada já se torna a sua própria história?” (LISPECTOR, 2005, p. 52). A mulher queimada, ao passo que descodifica sua reputação no imaginário daquela sociedade, descodifica também o processo de memória coletiva do ritual de crueldade, pois imprime nele um novo agenciamento coletivo de enunciação. A Pecadora, que acima de tudo pertenceu a si mesma, morreu saciada de vida e viveu em terra como se não tivesse pátria, nem leis: desterritorializada, nômade.

A adúltera que morreria silenciada num sinal de apagamento de sua identidade naquela sociedade, ao suscitar no olho coletivo a atenção à sua história e força identitária, garante com o inusitado sorriso da morte a descodificação de sua subjetividade na memória coletiva. Simultaneamente a esse processo de inversão, sobrepõe outra codificação no projeto de produção de memória coletiva do ritual de crueldade.

Ao estabelecer conexão diretamente com o imaginário dos espectadores da execução, o enigmático sorriso da morte da "carne passiva” pode denotar que existem alternativas de 
escolhas de um modo de existência vivo, intensivo, descodificado e desatrelado do recalcamento do processo desejante. O sorriso como linha de fuga, nessa perspectiva, aciona uma máquina de guerra nômade; quando capturada, ela se instaura como um efeito colateral dentro de um sistema.

Como a potência de um devir minoritário, o sorriso se configura como um vetor de desterritorialização que, de maneira quase estática, desertifica todos os espaços estriados no qual se encontra, atravessando todo o território e engendrando novas possibilidades de vida dentro das convenções das estruturas do aparelho estatal. A máquina de guerra, que se opera a partir do sorriso da Pecadora, instaura-se de modo a alisar todos os estriamentos, ruindo o discurso do agenciamento de poder, desestabilizando o conforto dos pensamentos colonizados, avariando a perpetuação do processo de produção de memórias dos corpos dóceis. A linguagem silenciosa da Pecadora, como linha de fuga, estabelece potencialmente o detonador do sistema de poder naquela sociedade: responde com criatividade à morte com a vida.

\section{CONSIDERAÇÕES FINAIS}

O dispositivo máquina de guerra, nessa perspectiva, não tem a guerra como objeto, "[...] mas passa a tê-la, necessariamente, quando se deixa apropriar pelo aparelho de Estado" (DELEUZE; GUATTARI, 1997, p. 15). Tanto o aparelho estatal quanto a máquina de guerra, para os filósofos, estão desatrelados da noção de instituição militar, violência, forças armadas ou qualquer outro aparato. Em outras palavras, a guerra estabelece-se sem derramamento de sangue e é manifestada pela linha de fuga criadora, que simboliza, por sua vez, a potência em devir atravessando os dispositivos de poder.

A manifestação não verbal da protagonista, ao expressar-se por meio do sorriso, acionada como máquina de guerra, ao mesmo tempo que se põe em fuga deixa rastros de destruição. Nesse sentido, a linguagem silenciosa da Pecadora evidencia-se como um potente mecanismo de ruína do campo inimigo.

A maneira de como a peça foi construída arrasta a linguagem para uma zona de indiscernibilidade; a protagonista desprovida de nome e de fala não possui referências e não é narrada, pois como uma entidade nômade não é possível particularizá-la. Portanto, é escorregadia, indefinida: ela prefere não falar? Seu silêncio e o sorriso ao abrir espaço para a fuga da linguagem também abrem espaço para uma confusa indeterminação, pois a linguagem encontra na peça um devir outro da língua.

Na perspectiva de uma linha de fuga, mesmo que aparente uma passiva entrega para a morte, ao fixar-se dentro do pensamento colonizado, o sorriso aqui parece funcionar como uma estratégica guerrilha silenciosa inventiva e criadora. Ele se infiltra no sistema e, progressivamente, a partir das reverberações de significações que ele exige do intelecto, nomadiza as dimensões da sociedade, alisando seus estriamentos e, em certa medida, desarmoniza o sistema de morte.

\section{REFERÊNCIAS}

ARISTÓTELES. Poética. Tradução Paulo Pinheiro. São Paulo: Ed. 34, 2015.

ARTAUD, A. O Teatro e seu Duplo. São Paulo: Martins Editora, 2006. 
DELEUZE; G.; GUATTARI, F. Mil platôs. Capitalismo e esquizofrenia 2. Tradução Aurélio Guerra Neto e Celia Pinto Costa. São Paulo: Ed. 34, 1995.

DELEUZE; G.; GUATTARI, F. Mil platôs. Capitalismo e esquizofrenia 5. Tradução Peter Pál Pelbart e Janice Caiafa. São Paulo: Ed. 34, 1997.

DELEUZE, G.; PARNET, C. Diálogos. Tradução Eloísa Araújo Ribeiro. São Paulo: Escuta, 1998.

FITZ, E. E.; NALINI, E. A pecadora queimada e os anjos harmoniosos: Clarice Lispector como dramaturga. Revista Cerrados, Brasília, v. 20, n. 32, p. 130-149, jun. 2011.

LISPECTOR, C. A Pecadora queimada e os Anjos harmoniosos. In: LISPECTOR, C. Outros escritos. Organização Teresa Montero e Lícia Manzo. Rio de Janeiro: Rocco, 2005. p. 47-57.

LISPECTOR, C. Fundo de gaveta. In: LISPECTOR, C. A legião estrangeira. Rio de Janeiro: Editora do Autor, 1964. p. 125-127.

LISPECTOR, C. Todos os contos. Organização Benjamin Moser. Rio de Janeiro: Rocco, 2016.

ORLANDI, E. P. As formas do silêncio: no movimento dos sentidos. Campinas: Unicamp, 1995.

SKEIKA, J.; OLIVEIRA, S. Ecos de uma linguagem (escrita) esquizofrênica em A paixão segundo G. H. de Clarice Lispector. Uniletras, Ponta Grossa, v. 36, n. 1, p. 11-21, jan./jun. 2014. DOI: https://doi.org/10.5212/uniletras.v36i1.6544 